Quim. Nova, Vol. 34, No. 8, 1468-1471, 2011

\title{
TRATAMENTO DE RESÍDUOS DE CORANTE POR ELETROFLOCULAÇÃO: UM EXPERIMENTO PARA CURSOS DE GRADUAÇÃO EM QUÍMICA
}

\author{
Sidney de Aquino Neto, Thiago Cavalheiro Magri, Gláucia Maria da Silva e Adalgisa Rodrigues de Andrade* \\ Departamento de Química, Faculdade de Filosofia, Ciências e Letras de Ribeirão Preto, Universidade de São Paulo, Av. Bandeirantes, \\ 3900, 14049-901 Ribeirão Preto - SP, Brasil
}

Recebido em 15/9/10; aceito em 11/3/11; publicado na web em 5/5/11

\begin{abstract}
TREATMENT OF WASTE DYE BY ELECTROFLOCCULATION: AN EXPERIMENT FOR UNDERGRADUATE IN CHEMISTRY. This paper describes the use of a simple experiment of electroflocculation for classroom in Chemistry. Parameters such as electrode material, current density and temperature direct influence the process efficiency. Due to the process low cost and efficient color removal, the methodology proposed has shown good potential for use in wastewater treatment. In addition, the proposed experiment allows discussion about environmental electrochemistry, introduction to concepts of water contamination by industry and university, and also about different alternatives in wastewater treatment used nowadays. Finally, the very easy operation make possible to easy adapt this experiment for high school and elementary school.
\end{abstract}

Keywords: electroflocculation; wastewater; dyes.

\section{INTRODUÇÃO}

A atividade humana, seja ela industrial ou não, é um grande agente gerador de resíduos. Corantes, óleos, graxas e muitos outros subprodutos acarretam diversos problemas ao meio ambiente, sendo que uma importante parcela do processo de contaminação pode ser atribuída às atividades das refinarias de petróleo, das indústrias químicas, têxteis e farmacêuticas, da agricultura, esgotos sanitários e resíduos domésticos. Em vista da escassez dos recursos hídricos disponíveis, diversas alternativas e novas tecnologias têm sido desenvolvidas para o tratamento desses compostos orgânicos tóxicos.

As águas residuais provenientes das indústrias têxteis impõem sérios problemas ambientais e correspondem a uma das principais fontes de contaminação aquosa. O tingimento e as operações de acabamento da indústria têxtil produzem grandes quantidades de resíduos com elevadas cargas orgânica e inorgânica, além de elevada coloração. Estes resíduos possuem também grande quantidade de surfactantes e agentes quelantes que podem provocar a eutrofização, além de perturbações na vida aquática. Sua remoção da água, portanto, se faz necessária para oferecer um ambiente limpo e, por isso, tem atraído à atenção de químicos, ambientalistas, tecnólogos e empresários. Embora não se saiba com exatidão a quantidade de corantes produzida pela indústria, atualmente cerca de 100.000 tipos de corantes e pigmentos são utilizados em atividades industriais, o que corresponde a 7 x $10^{5} \mathrm{t}$ anuais, que geram $850 \mathrm{~m}^{3}$ de efluente por dia. ${ }^{1-3}$ Os azo-corantes, que possuem o grupamento $\mathrm{R}-\mathrm{N}=\mathrm{N}-\mathrm{R}$, , representam cerca de $70 \%$ de todos os corantes têxteis produzidos pela indústria. Este tipo de efluente apresenta alta coloração e alto valor de demanda química de oxigênio (DQO), acarretando poluição visual e alteração na biota, além de ser cancerígeno.

A síntese de corantes, tais como laranja II e azul de índigo, geralmente é realizada em aulas experimentais dos cursos de gra-

*e-mail: ardandra@ffclrp.usp.br duação em Química. No Departamento de Química da Faculdade de Filosofia Ciências e Letras (FFCL) de Ribeirão Preto, por exemplo, o azo-corante laranja II é utilizado como exemplo em experimentos de síntese orgânica.

Em solução aquosa, o corante laranja II (Figura 1) existe predominantemente como um tautômero ceto, e o fato do grupo azo ser um forte retirador de elétrons faz com que este corante seja protegido do ataque das oxigenases. Desta maneira, os processos convencionais aeróbios de tratamento de águas residuais, em geral, não podem descolorir eficientemente efluentes de azo-corantes.

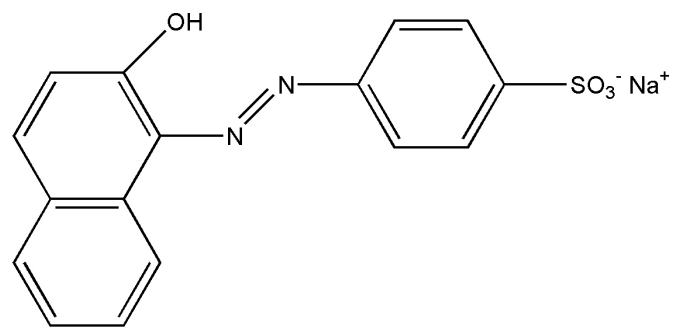

Figura 1. Representação estrutural do azo-corante laranja II

\section{Técnicas de tratamento de efluentes}

Hoje em dia, há uma grande variedade de métodos físicos, químicos e biológicos disponíveis para o tratamento de águas residuais provenientes de diversas atividades humanas. O objetivo desses tratamentos é realizar a transferência de fase do material do efluente de interesse e, se possível, transformar substâncias que possuem elevado grau de toxicidade em compostos inertes, como $\mathrm{CO}_{2}$ e $\mathrm{H}_{2} \mathrm{O}$, ou em outros menos agressivos ao meio ambiente. Dentre os diversos tratamentos físicos existentes, a adsorção em carvão ativado, coagulação e flotação são bastante eficientes na remoção dos compostos de interesse de matrizes complexas. Esses se enquadram como uma tecnologia não destrutiva ou de transferência de fase, que necessitam de uma disposição final para o poluente. ${ }^{4} \mathrm{~A}$ incineração do resíduo 
sólido é uma técnica muito utilizada, com alto custo de operação e manutenção e pode gerar, também, alguns compostos de nível tóxico elevado, como as dioxinas e furanos, que são lançados na atmosfera. O tratamento biológico é o método mais utilizado para a remoção de resíduos, já que possui baixo custo, porém, sua cinética de degradação é lenta e sua ação é limitada a compostos de baixa toxicidade e a concentrações baixas de contaminantes. ${ }^{5,6}$

O tratamento eletroquímico surge como uma alternativa para realizar a oxidação e não apenas a transferência de fase do material orgânico de interesse. Estudos mostram que se pode alcançar elevada eficiência de degradação com esta técnica. ${ }^{7,8}$ Grande atenção é dada também aos conhecidos processos oxidativos avançados (POA), definidos como processos nos quais o radical hidroxila é o principal oxidante envolvido. Esse radical é um poderoso oxidante $\left(\mathrm{E}_{\mathrm{o}}=2,80 \mathrm{~V}\right)$ que conduz a um processo bastante eficaz. Os POAs podem ser classificados como homogêneos e heterogêneos. Destacam-se entre eles, os processos Fenton e fotoFenton, a fotocatálise e a fotocatálise heterogênea e, também, a ozonização (Tabela 1). A grande vantagem da utilização dessas metodologias no tratamento de poluentes orgânicos reside no fato de não produzirem subprodutos particulados, que necessitem de uma disposição final especial.

Tabela 1. Classificação dos processos oxidativos avançados utilizad

\begin{tabular}{lcc}
\hline Sistema & Com irradiação & Sem irradiação \\
\hline Homogêneo & $\mathrm{O}_{3} / \mathrm{H}_{2} \mathrm{O}_{2} / \mathrm{UV}$ & $\mathrm{O}_{3} / \mathrm{pH}>10$ \\
$\mathrm{O}_{3} / \mathrm{UV}$ & $\mathrm{O}_{3} / \mathrm{H}_{2} \mathrm{O}_{2}$ \\
& $\mathrm{H}_{2} \mathrm{O}_{2} / \mathrm{UV}$ & $\mathrm{Fe}^{+2} / \mathrm{H}_{2} \mathrm{O}_{2}$ \\
& $\mathrm{Fe}^{+2} / \mathrm{H}_{2} \mathrm{O}_{2} / \mathrm{UV}$ & \\
\hline Heterogêneo & Semicondutor/UV & \\
& Semicondutor $/ \mathrm{H}_{2} \mathrm{O}_{2} / \mathrm{UV}$ & \\
\hline
\end{tabular}

Apesar da eficiência desses processos, os mesmos se restringem a baixas concentrações de contaminantes e têm um custo elevado. No entanto, o uso combinado dos POAs pode contribuir para a superação das desvantagens de cada processo, aumentando, assim, o desempenho global de um tratamento. ${ }^{9}$

\section{Eletrofloculação}

O processo da eletrofloculação, também chamado de eletrocoagulação ou eletroflotação é essencialmente um processo eletrolítico que envolve a desestabilização de poluentes emulsificados, ou em suspensão, em meio aquoso. Basicamente, este processo ocorre em três etapas. ${ }^{10}$

Na primeira, o coagulante é gerado in situ pela oxidação de um ânodo metálico (M) de sacrifício; assim que os respectivos cátions são gerados na fase anódica, estes reagem com moléculas de água para formação dos respectivos hidróxidos e poli-hidróxidos. Os materiais mais utilizados como ânodos de sacrifício são o ferro e o alumínio, devido a seu baixo custo, disponibilidade e eficácia. Paralelamente, tem-se a eletrólise da água e a formação de microbolhas de oxigênio no ânodo e hidrogênio no cátodo que carregarão, na última etapa, o material floculado para a superfície:

No ânodo:

$$
\begin{gathered}
M_{(s)} \rightarrow M_{(a q)}^{n+}+n e^{-} \\
2 H_{2} O_{(l)} \rightarrow 4 H_{(a q)}^{+}+O_{2(g)}+4 e^{-}
\end{gathered}
$$

No cátodo:

$$
\begin{gathered}
M_{(a q)}^{n+}+n e^{-} \rightarrow M_{(s)} \\
2 H_{2} O_{(l)}+2 e^{-} \rightarrow 2 \mathrm{OH}_{(a q)}^{-}+H_{2(g)}
\end{gathered}
$$

Na segunda etapa, os hidróxidos formados adsorvem-se em partículas coloidais originando os flóculos e tem-se o transporte dessas espécies que entram em contato com as impurezas. A remoção dos poluentes pode ocorrer tanto por complexação como por atração eletrostática e posterior coagulação.

Na última etapa do processo ocorre a flotação, em decorrência da formação das microbolhas que são geradas da eletrólise da água (Figura 2).

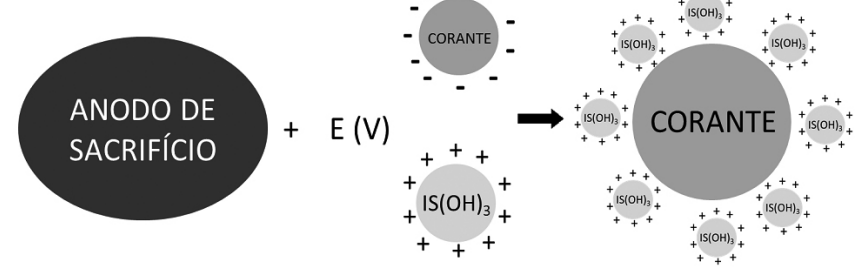

Figura 2. Ilustração do processo de adsorção e formação das partículas coloidais que geram os flóculos com as moléculas de corantes. IS = ion de sacrifício: $\mathrm{Al}(\mathrm{OH})_{3}$ ou $\mathrm{Fe}(\mathrm{OH})_{3}$, conforme esquema empregado

\section{Abordagem do tratamento eletroquímico de resíduos no ensino de química}

Na literatura, podem ser encontradas várias propostas de procedimentos experimentais envolvendo aplicações da eletroquímica para a melhoria do ambiente. ${ }^{11-13}$ Ibanez e colaboradores, ${ }^{11}$ por exemplo, propuseram um dispositivo eletroquímico equipado com ânodo de sacrifício de ferro para remoção de poluentes via formação de hidróxidos metálicos; a oxidação indireta de soluções contendo corantes e remoção de alguns compostos orgânicos; ${ }^{12}$ além da investigação das diferentes condições experimentais para a preparação eletroquímica do ferrato, no intuito de introduzir os conceitos básicos de química ambiental. ${ }^{13}$ Entretanto, nenhum desses trabalhos descreve a aplicação dos experimentos em sala de aula.

No Brasil, tanto no ensino superior como no ensino médio, as possibilidades existentes em termos de tratamento de poluentes orgânicos do meio ambiente praticamente não são discutidas e, tampouco, são propostos experimentos com esse objetivo. Constata-se assim que os currículos dos cursos de Química dão pouca relevância às questões ambientais relacionadas à utilização e tratamento de compostos orgânicos persistentes.

No intuito de contribuir para o enriquecimento da formação em Química, apresenta-se neste trabalho a elaboração, aplicação e avaliação de um experimento simples de tratamento de resíduo por eletrofloculação para uso em aulas experimentais.

A escolha da eletrofloculação justifica-se por ser o método caracterizado por instrumentação e operações simples, curto tempo de experimento, além da sua eficiência na remoção de poluentes de águas residuais de indústrias têxteis, urbanas, aterros de lixo, óleos, metais entre outros. ${ }^{14-18}$

\section{METODOLOGIA}

O desenvolvimento deste trabalho foi feito em duas etapas. $\mathrm{Na}$ primeira, o objetivo foi o desenvolvimento de uma metodologia experimental que possibilitasse a discussão e o entendimento dos diversos parâmetros que influenciam o processo da eletrofloculação. Nesse intuito, foi elaborado um experimento de eletrofloculação que foi aplicado nas aulas experimentais da disciplina Análise Instrumental da FFCL de Ri- 
beirão Preto, USP. Na segunda etapa, procurou-se avaliar o experimento proposto através de entrevistas com os alunos da referida disciplina.

\section{MATERIAIS E MÉTODOS}

Como ânodos de sacrifício foram utilizados pregos (como fonte de íons $\mathrm{Fe}^{+2}$ e $\mathrm{Fe}^{+3}$ ) e anéis de latinha de refrigerante (como fonte de íons $\mathrm{Al}^{+3}$ ), o contraeletrodo sempre foi idêntico ao eletrodo de trabalho. As eletrólises foram realizadas utilizando-se uma fonte de corrente constante de $20 \mathrm{~V}$. Como exemplo de um azo-corante utilizou-se o corante laranja II, que foi preparado previamente em uma aula da disciplina de Química Orgânica Experimental do curso de Licenciatura em Química da FFCLRP. Ressalta-se aqui que podem ser utilizados outros corantes comuns como exemplo de efluente, tais como azul de índigo, indicadores de $\mathrm{pH}$, corantes alimentícios, entre outros.

O espectro de absorbância do corante laranja II apresenta uma banda de absorbância na região do visível em $480 \mathrm{~nm}$ e por isso sua determinação pode ser realizada com facilidade por meio de um espectrofotômetro. As análises por espectrofotometria do UV-Vis foram realizadas em um espectrofotômetro Varian modelo Cary 50. Desta maneira por meio de uma curva padrão, no intervalo de concentração de 1 a $25 \mathrm{mg} \mathrm{L}^{-1}$ do corante, pode-se acompanhar a cinética de descoloração ao longo das eletrólises. Como eletrólito suporte utilizou-se uma solução de sulfato de sódio $\left(25 \mathrm{~g} \mathrm{~L}^{-1}\right)$, que atua como catalisador na precipitação e coagulação dos hidróxidos além de elevar a condutividade da solução. Como exemplo de um efluente preparou-se uma solução adicionando-se em um béquer de $100 \mathrm{~mL}$ (utilizando-se o mesmo como cela eletroquímica) $3 \mathrm{~mL}$ da solução estoque de corante ( $400 \mathrm{mg} \mathrm{L}^{-1}$ ) em $50 \mathrm{~mL}$ de eletrólito suporte.

Antes de iniciar os experimentos, os eletrodos de sacrifício devem ser lixados para retirar a camada de óxidos devido à passivação que o eletrodo sofre em contato com o ar. No caso do alumínio, faz-se necessário aplicar por alguns minutos uma corrente $\left(10 \mathrm{~mA} \mathrm{~cm}^{2}\right)$ ou realizar uma limpeza com solvente orgânico (isso se deve ao fato desse material ser recoberto por uma camada de verniz na sua fabricação). É necessário também realizar uma medida aproximada da área de ambos os eletrodos de sacrifício.

Para avaliar os parâmetros que influenciam no processo da eletrofloculação, além da variação do material do eletrodo de sacrifício, três diferentes densidades de corrente foram empregadas. Utilizando ferro como eletrodo de sacrifício aplicou-se, respectivamente, 1,2; 2,4 e 4,8 $\mathrm{mA} \mathrm{cm}{ }^{-2}$. Já para o ânodo de $\mathrm{Al}$, densidades menores de corrente foram empregadas - 0,15; 0,8 e 2,4 $\mathrm{mA} \mathrm{cm}^{-2}$. Além disso, avaliou-se o efeito da temperatura no processo de eletrofloculação; utilizando-se Fe como eletrodos de sacrifício, aplicou-se $1,2 \mathrm{~mA} \mathrm{~cm}^{-2}$ em um banho termostático a 25 e a $50{ }^{\circ} \mathrm{C}$. O tempo de todas as eletrólises foi de $30 \mathrm{~min}$. Ao final dos experimentos pode-se optar por uma filtração simples ou aguardar que o material floculado decante para então realizar as medidas de absorbância das soluções.

\section{Percepção dos alunos}

Após a realização do experimento de eletrofloculação, todos os alunos foram entrevistados informalmente a fim de se obter um diagnóstico da sua percepção e sensibilização, bem como do conhecimento construído. As respostas obtidas foram analisadas qualitativamente ${ }^{19}$ para avaliar a efetividade do experimento em seu objetivo maior, que é a discussão acerca do tratamento de poluentes orgânicos.

\section{RESULTADOS E DISCUSSÃO}

\section{Teste do experimento}

O espectro UV-Vis obtido a partir de uma solução diluída (22,6 mg $\left.\mathrm{L}^{-1}\right)$ do corante laranja II mostra que esse composto apresenta uma banda de absorção bem definida com um máximo em $480 \mathrm{~nm}$. Além disso, a curva de calibração para esse composto indica que a intensidade de absorção da luz pelo corante segue a lei de Lamber-Beer.

Nas Figuras 3a e b são apresentados os espectros obtidos após a realização dos experimentos de eletrofloculação, em várias densidades de corrente e com diferentes materiais eletródicos. Constatou-se que uma maior eficiência de descoloração da solução de corante é obtida com o aumento da densidade de corrente aplicada. Tal fato é justificado pela formação de mais espécies coagulantes em elevadas densidades de corrente, que aceleram o processo de formação das partículas coloidais e, consequentemente, aumentam a eficiência do processo. Outrossim, em maiores densidades de corrente, o potencial do eletrodo pode ser suficiente para oxidar também as espécies de corante, auxiliando no processo de descoloração da solução.
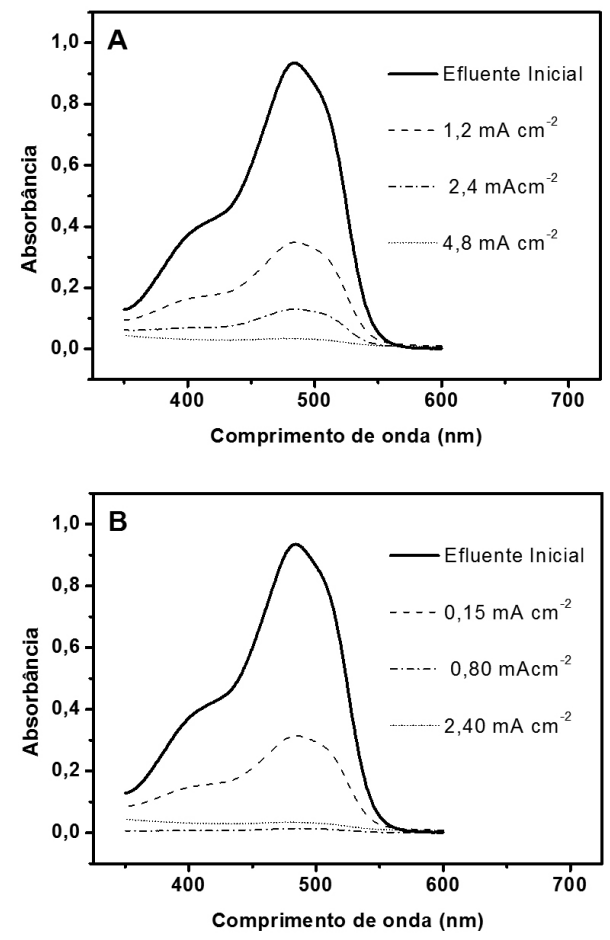

Figura 3. Espectros dos efluentes após 30 min de eletrólise, utilizando-se (a) $\mathrm{Fe} \mathrm{e} \mathrm{(b)} \mathrm{Al} \mathrm{como} \mathrm{eletrodos} \mathrm{de} \mathrm{sacrifício}$

A partir dos espectros da Figura 3b, vê-se ainda que o tratamento realizado com os ânodos de $\mathrm{Al}$ apresenta maior eficiência de descoloração da solução de corante em relação ao tratamento com Fe. Como apresentado na Figura 4, utilizando-se Fe como ânodos de sacrifício, a descoloração total da solução de corante é obtida apenas em correntes igual ou superiores a $4,8 \mathrm{~mA} \mathrm{~cm}^{-2}$. Nas eletrólises em que foi empregado Al, observa-se descoloração total da solução de corante em densidade de corrente de $2,4 \mathrm{~mA} \mathrm{~cm}^{-2}$.

Para avaliar o efeito cinético no processo de eletrofloculação, foram realizadas eletrólises utilizando-se Fe como eletrodo de sacrifício, em diferentes temperaturas, mantendo a densidade de corrente constante em $1,2 \mathrm{~mA} \mathrm{~cm}^{-2}$ por $30 \mathrm{~min}$. A Figura 5 apresenta o comportamento obtido nas eletrólises em 25 e $50^{\circ} \mathrm{C}$. A partir dos espectros representados na Figura 5, observa-se que a temperatura (ou efeito cinético) é um fator que influencia diretamente na eficiência do processo de eletrofloculação, uma vez que um aumento na temperatura propiciou um aumento significativo da descoloração da solução de corante para um mesmo tempo de tratamento. Tal como o efeito da densidade de corrente, que acelera o processo de formação dos flóculos, a influência da temperatura no processo pode ser compreendida pela rapidez com que são formados os 


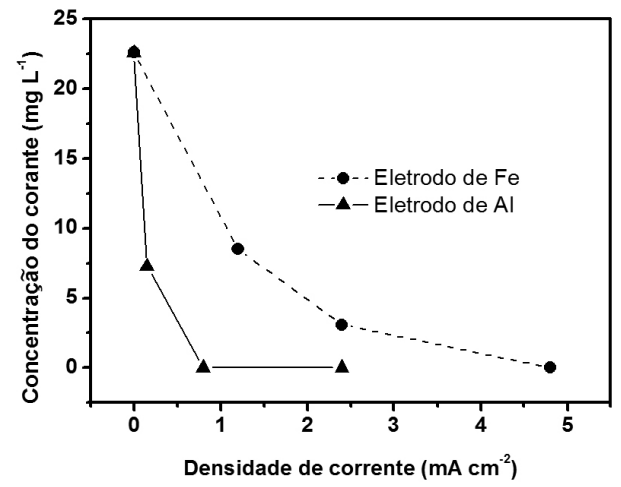

Figura 4. Comportamento dos diferentes eletrodos de sacrifício em função da densidade de corrente aplicada durante o processo de eletrofloculação

flóculos em elevadas temperaturas. O aumento na temperatura também eleva a condutividade iônica do eletrólito, diminuindo assim o potencial aplicado. Desta maneira, a eficácia do processo deve aumentar não só pelo melhor desempenho na geração de hidróxidos metálicos, como também na oxidação do corante. Se ambos os processos forem mais eficientes, maior será a descoloração da solução de corante.

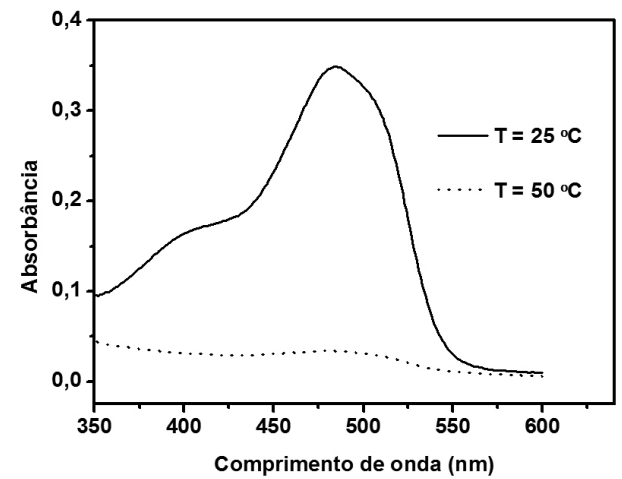

Figura 5. Influência da temperatura no processo da eletrofloculação utilizando-se Fe como eletrodo de sacrifício aplicando-se 1,2 $\mathrm{mA} \mathrm{cm}^{-2}$ durante $30 \mathrm{~min}$

De maneira geral, o experimento proposto demonstrou que a eletrofloculação ou eletrocoagulação apresenta grande potencial para ser utilizada no tratamento de águas residuais, devido ao baixo custo de materiais empregados, baixo consumo de energia e grande eficácia na remoção de cor. No entanto, assim como os demais processos, a eletrofloculação possui limitações, tais como a necessidade de reposição do ânodo de sacrifício e de uma solução condutora e tem como grande desvantagem a necessidade de uma disposição final para o material floculado. Numa escala industrial, a geometria do reator a ser utilizado no tratamento, é um fator importante e necessita de adaptação para sua utilização em larga escala.

\section{Percepção dos alunos}

Entre os aspectos positivos, os alunos citaram que o experimento conseguiu abordar a maioria dos conceitos relativos à eletrofloculação, além de contribuir para a introdução de outros conteúdos ainda não abordados (formação de outras espécies tóxicas em solução, como os compostos organoclorados; potencial de oxidação de compostos orgânicos; reação de oxidação da água, estão entre os mais citados nos questionários). Também foram elogiados aspectos como o baixo custo dos materiais utilizados e a facilidade de obtenção dos mesmos.

Aspectos como dificuldade de aplicação em larga escala, consumo elevado de energia e descarte dos resíduos tratados foram citados como pontos negativos da técnica de eletrofloculação.

Além disso, foi possível constatar a mudança de atitude dos alunos em relação ao descarte de resíduos e à reciclagem, pois, segundo eles, eliminar compostos tóxicos com as metodologias atualmente disponíveis "não compensa", sendo muito mais fácil não poluir do que tratar.

\section{CONSIDERAÇÕES FINAIS}

O experimento de eletrofloculação proposto permite ao professor aprofundar conceitos básicos de eletroquímica (material eletródico, densidade de corrente aplicada, entre outros) e de química ambiental (geração de efluentes tanto na indústria quanto nas atividades experimentais do ensino superior). Além de ser excelente para introdução de conceitos de tratamento de poluentes orgânicos e contaminação ambiental, essa prática pode fomentar a discussão das vantagens e desvantagens das diversas tecnologias de tratamento, permitindo ao aluno ampliar os conceitos de atuação e responsabilidade do profissional de Química no exercício da sua profissão.

Devido à simplicidade operacional envolvida no processo da eletrofloculação, este experimento pode ser facilmente adaptado para o ensino fundamental e médio utilizando-se baterias ou pilhas ao invés de um galvanostato e indicadores ou corantes alimentícios como exemplos de efluentes, como citado na literatura. ${ }^{20}$

\section{AGRADECIMENTOS}

Ao CNPq e à CAPES pelas bolsas de mestrado concedidas, ao Departamento de Química da FFCLRP-USP pela infraestrutura disponibilizada e aos graduandos que participaram da pesquisa.

\section{REFERÊNCIAS}

1. Forgacs, E.; Cserhati, T.; Oros, G.; Environ. Int. 2004, 30, 953.

2. Robinson, T.; McMullan, G.; Marchant, R.; Nigam, P.; Bioresour. Technol. 2001, 77, 247.

3. Papic, S.; Koprivanac, N.; Bozic, A. L.; Metes, A.; Dyes Pigm. 2004, 62, 291.

4. Jae-Wook, L.; Seung-Phil, C.; Ramesh, T.; Wang-Geun, S.; Hee, M,; Dyes Pigm. 2006, 69, 196.

5. Kapdan, I. K.; Alparslan, S.; Enzyme Microb. Technol. 2005, 36, 273.

6. Alinsafi, A.; da Motta, M.; Le Bonte, S.; Pons, M. N.; Benhammou, A.; Dyes Pigm. 2006, 69, 31.

7. Aquino Neto, S.; De Andrade, A. R.; Electrochim. Acta 2009, 54, 2039.

8. Aquino Neto, S.; De Andrade, A. R.; J. Appl. Electrochem. 2009, 39, 18

9. Renk, R. R.; Energy Prog. 1998, 8, 205.

10. Crespilho, F. R.; Rezende, M. O. O.; Eletroflotação: Princípios e Aplicações, RiMa Editora: São Carlos, 2004.

11. Ibanez, J. G.; Singh, M. M.; Pike, R. M.; Szafran, Z.; J. Chem. Educ. 1998, 75,634 .

12. Ibanez, J. G.; Quimica Nova na Escola 2002, n 15, 45.

13. Ibanez, J. G.; Tellez-Giron, M.; Alvarez, D.; Garcia-Pintor, E.; J. Chem. Educ. 2004, 81, 251.

14. Chen, G.; Sep. Purif. Technol. 2004, 38, 11.

15. Mollah, M. Y. A.; Schennach, R.; Parga, J. P.; Cocke, D. L.; J. Hazard. Mater. 2001, B84, 29.

16. Rajeshwar, K.; Ibanez, J. G.; Swain, G. M.; J. Appl. Electrochem. 1994, 24 , 1077.

17. Lin, S. H.; Lin, C.S.; Desalination 1998, 120, 185.

18. Adhoum, N.; Monser, L.; Chem. Eng. Process. 2004, 43, 1281.

19. Ludke, M.; André, M. E. D. A.; Pesquisa em educação: abordagens qualitativas, EPU: São Paulo, 1990.

20. Aquino Neto, S.; Monografia do curso de Licenciatura em Química, Universidade de São Paulo, Brasil, 2008. 